\title{
DE DE GRUYTER \\ DOI: 10.1515/orga-2016-0013 \\ OPEN \\ Understanding the Structural Complexity of Induced Travel Demand in Decision-Making: A System Dynamics Approach
}

\author{
Juan S. Angarita-Zapata1, Jorge A. Parra-Valencia², Hugo H. Andrade-Sosa1 \\ ${ }^{1}$ School of Systems Engineering and Informatics, Universidad Industrial de Santander, \\ SIMON Research Group, Colombia \\ juan.angarita1@correo.uis.edu.co (corresponding author) \\ ${ }^{2}$ School of Systems Engineering, Universidad Autónoma de Bucaramanga, \\ Systems Thinking Research Group, Colombia
}

\begin{abstract}
Background and purpose: Induced travel demand (ITD) is a phenomenon where road construction increases vehicles' kilometers traveled. It has been approached with econometric models that use elasticities as measure to estimate how much travel demand can be induced by new roads. However, there is a lack of "white-box" models with causal hypotheses that explain the structural complexity underlying this phenomenon. We propose a system dynamics model based on a feedback mechanism to explain structurally ITD.

Methodology: A system dynamics methodology was selected to model and simulate ITD. First, a causal loop diagram is proposed to describe the ITD structure in terms of feedback loops. Then a stock-flows diagram is formulated to allow computer simulation. Finally, simulations are run to show the quantitative temporal evolution of the model built.

Results: The simulation results show how new roads in the short term induce more kilometers traveled by vehicles already in use; meanwhile, in the medium-term, new traffic is generated. These new car drivers appear when better flow conditions coming from new roads increase attractiveness of car use. More cars added to vehicles already in use produce new traffic congestion, and high travel speeds provided by roads built are absorbed by ITD effects.

Conclusion: We concluded that approaching ITD with a systemic perspective allows for identifying leverage points that contribute to design comprehensive policies aimed to cope with ITD. In this sense, the model supports decision-making processes in urban contexts wherein it is still necessary for road construction to guarantee connectivity, such as the case of developing countries.
\end{abstract}

Keywords: induced travel demand; system dynamics; decision-making; dynamic modeling.

\section{Introduction}

Mobility is the necessity to travel that is derived from the desire to participate in economic and social activities in urban areas. Traveling between different locations involves an expenditure of time. However, negative implications appear when movements on roads are accomplished by spending more time than usual due to traffic congestion
(Hills, 1996). In intuitive decision-making processes, road construction is a well-known policy that increases travel speeds and reduces travel delays (Hong et al., 2011; Noland and Lem, 2002). Nevertheless, evidence of a shortand medium-term correlation between road construction and travel demand has been found (Graham et al., 2014; Hanse, 1995). This phenomenon is known as induced travel demand (ITD) in which new roads, expressed as linear

Received: May 6, 2016; revised: July 2, 2016; accepted: July 26, 2016 
kilometers, induce increases in the number of kilometers traveled by vehicles.

ITD calls into question the effectiveness of road construction as a single and sufficient policy to address traffic congestion (Ladd, 2012). Several studies have approached ITD with econometric models that use elasticities as measure to estimate how much travel demand can be induced by new roads (Currie and Delbosc, 2010; Handy, 2014; Litman, 2015; Noland, 2004; Özuysal and Tanyel, 2008). Those models are built with forecasting purposes to match sets of outputs between specified ranges of accuracy without claims of causality in their structure (Barlas, 1996). They do not focus on providing structural explanations of the counterintuitive behavior in which mobility tends to be saturated despite building new roads.

Although econometric models corroborate the existence of ITD and quantify it, explaining this phenomenon structurally allows designing comprehensive policies that go beyond road construction to effectively address traffic congestion. However, to do this, ITD should be approached from a systemic perspective to suggest sizing up this phenomenon, placing it in a wide enough context, and thinking about it as a system in the same way that every social concern must be approached (Bunge, 2014). This implies recognizing and defining elements that interact between road construction and motorized travel demand as elements that are strongly linked and influence each other in a whole system and whose interactions determine ITD behavior. The latest avoids reductionist thinking in which linear cause-effect relationships are studied in isolation.

In this sense, "white-box" models can propose representations about the structural complexity of ITD. Through system dynamics (SD) models, which are "causal-descriptive" models, it is possible to formulate statements of how ITD actually works. These models are built to understand why certain phenomena occur. This question is answered using a feedback structure that explains the occurrence of ITD over time (Sterman, 2000); this means that the feedback structure produces a behavior that can be similar to ITD behavior. Therefore, the feedback mechanism is conceived as a dynamic hypothesis of ITD based on a fundamental premise of the systems dynamics paradigm: to similar causal structures correspond similar behaviors (Andrade et al., 2001; Forrester, 1971).

In this paper, we highlight the structural complexity underlying ITD. These insights are based on an SD model whose feedback structure is a dynamic hypothesis that explains and simulates ITD by road construction. The SD model represents a complex mobility phenomenon that is corroborated and measured through econometric models using a systemic approach. This means including the linear relationship between kilometers traveled and kilometers built within a structure of cyclical influence from which ITD dynamically emerges using SD modeling tools.

\section{Bibliographic review}

The phenomenon of induced travel demand (ITD) was recognized even before the automobile age (Ladd, 2012). However, serious attention began only in the 1980 s, especially in the UK (Goodwin, 1992). During that time, scholars in the USA carried out statistical works to discuss and corroborate this phenomenon (Cervero, 2001; Noland, 2001). Since the 1990s, several studies using econometric models have produced more solid evidence about the existence of ITD (Duranton and Turner, 2011; Handy, 2014; Hymel et al., 2010; Litman, 2010; Noland, 2004; Özuysal and Tanyel, 2008). These confirmations contradict the long-term benefits of road construction on mobility. As a result, road construction in developed countries is no longer an exclusive policy to reduce traffic congestion.

However, in developing countries, rapid urban sprawl, high population growth, raised motorization rates and great traffic congestion have promoted a perceived need of more roads among transport policy-makers. Currently, these countries invest huge budgets for new and better roads to solve the issues described above. Nevertheless, despite available evidence about ITD in countries in Europe and North America, we have not found works that discuss ITD and evaluate its possible implications in developing countries under their current road construction scenarios. It is probable that if econometric models were used to assess how much travel demand can be induced by road construction projects, the results would show how the building policy increases the quantity of motorized travel in a long run time horizon.

Assuming as a fact the increment of motorized travel after road construction, regardless of the precise quantity of such increases, a representation with a system dynamics (SD) model of ITD provides a modeling tool that improves the decision-making process in developing countries. The SD model enhances the level of understating about the structural complexity of ITD. The better this phenomenon is known this phenomenon, the better comprehensive policies in mobility would be designed, taking into account that road facilities are still necessary to guarantee connectivity in developing urban cities.

We performed a bibliographic review that covers the period between 1990 and 2015. All papers reviewed were made under an econometric approach wherein elasticities are the primary measure to corroborate and quantify ITD. However, we did not find papers with a "causal-descriptive" or system dynamics approach. This supports the statement that there is a lack of "white-box" models with causal hypothesis to represent the structural complexity of ITD, based on available statistical evidence provided by econometric models. 


\section{Materials and Method}

System dynamics (SD) is a methodology based on feedback control theory equipped with mathematical simulation models by computer, which uses linear and non-linear differential equations. Jay Forrester at Massachusetts Institute of Technology developed this approach in the 1960s. Since then, it has been employed to address complex issues in various fields such as urban dynamics (Forrester, 1969), business and management (Sterman, 2000), education and learning (Andrade et al., 2014; Forrester, 1994), and economy and environment (Ford, 1999). The purpose of SD in these areas has focused on explaining structure and modelling complex phenomena that are represented as systems for understanding their behavior over time.

Building an SD model involves an iterative process. In the progression from one step to the next, the modeler moves backward and forward through each methodological tool that SD offers to create a model as an abstraction of a real phenomenon (Sterman, 2000). For this paper, we assumed these methodological tools as a set of languages that each represents a particular view of the model (Andrade et al., 2001). This methodological assumption corresponds to the modeling methodology of "five languages" that was proposed by Hugo Andrade et al. (2001) and is shown in Figure 1. The model was built with Evolución
$4.5^{1}$, a software platform developed by the SIMON ${ }^{2}$ research group at Universidad Industrial de Santander (Colombia) to build SD models.

\section{Results}

In this section, we expose the model that was built using each language of Figure 1. The purpose of this model is to propose a dynamic explanation in terms of circular causality of induced travel demand as emerging phenomenon between road construction and motorized travel demand. We did not take into account alternative means of transport, and the benefit of road construction inducing more travel demand is travel speed. Moreover, a specific urban context with mobility features is used to calibrate the basic model parameters.

\subsection{System verbalization}

The Metropolitan Area of Bucaramanga (MAB) is a metropolitan zone located in the department of Santander, Colombia, with an estimated population of $1,113,522$ people. It is composed of four cities: Bucaramanga (capital city of Santander), Floridablanca, San Juan de Girón and Piedecuesta. They are linked geographically and commercially, and transportation is a key element that influences the way

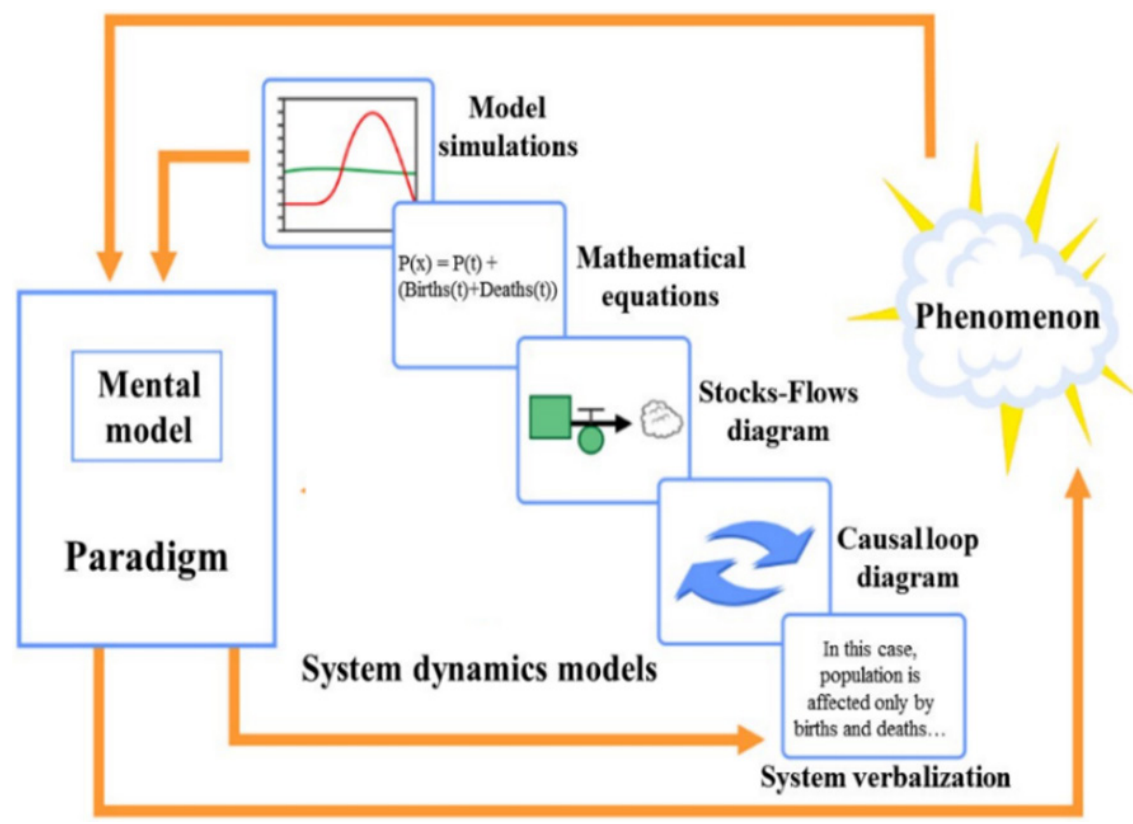

Figure 1: The methodology of "five languages" used to build the SD model. Source: adapted from (Andrade et al., 2001)

1 More information about Evolución software is available at: Andrade, H. H., Lince, E., Hernandez, A. E., Monsalve, A. J. (2010). Evolución: herramienta software para modelado y simulación con dinámica de sistemas. Revista de Dinámica de Sistemas Vol. 4 , Núm. 1, ISSN: 0718-1884.

2 For more information about SIMON research group, please visit www.simon.uis.edu.co 
in which people do their daily activities along the MAB. MAB'S fleet consists mostly of private vehicles (cars, vans and campers) that represent $38 \%$ of the total fleet. Additionally, there is a motorization rate of 442 vehicles per 1,000 people (Observatorio Metropolitano de Bucaramanga, 2014); meanwhile, road supply has built approximately 1,300 kilometers of road, and several road construction projects are underway that require great budgets to increase the number of kilometers available (Secretaría de Infraestructura de Bucaramanga, 2001). However, according to the evidence reviewed of induced travel demand in cities abroad, we suggest that this one-side policy will generate, at best, modest results in MAB.

\subsection{Causal Loop Diagram (CLD)}

The proposed CLD can be seen in Figure 2, and a brief description of each variable is shown below. According to Figure 2, the CLD includes two types of travel conditions on roads: the first type corresponds to potential conditions. They represent the level of service on roads calculated on the basis of vehicles that the kilometers built can hold at average flow conditions, including the whole fleet of private vehicles; this includes cars in use and cars that do not travel because of traffic congestion ${ }^{3}$. The second type corresponds to real conditions that represent the level of service on roads only based on cars traveling and the road capacity in terms of vehicles that the kilometers built can support.

- Kilometers Built: This is the available road infrastructure expressed as linear kilometers.

- Road Congestion Index: This represents the state of mobility as a ratio between kilometers traveled by cars and kilometers built. This index takes values between zero and one. Values closer to zero represent uncongested mobility. Values closer to one correspond to traffic congestion on the available road infrastructure.

- Fleet Growth: This represents the average growth of private vehicles in the Metropolitan Area of Bucaramanga. The flow rate at which the fleet increases is influenced by a motorization rate of 442 vehicles per 1.000 people. This growth rate includes social and economic elements that also increment travel demand growth and that are not specified within this model.

- Potential Level of Service (LoS): Thus represents the potential flow conditions on roads that change depending on values of a ratio, a dimensionless load factor, between fleet growth and vehicles that the kilometers built can hold at an average flow of 3,200 vehicles/hour and a service travel speed of 60 kilometers/hour. The scale of LoS has six discrete values ranging from $\mathrm{A}$ to $\mathrm{F}$, which can be seen in Table 1. Each discrete range is associated with an average range of potential travel speeds.

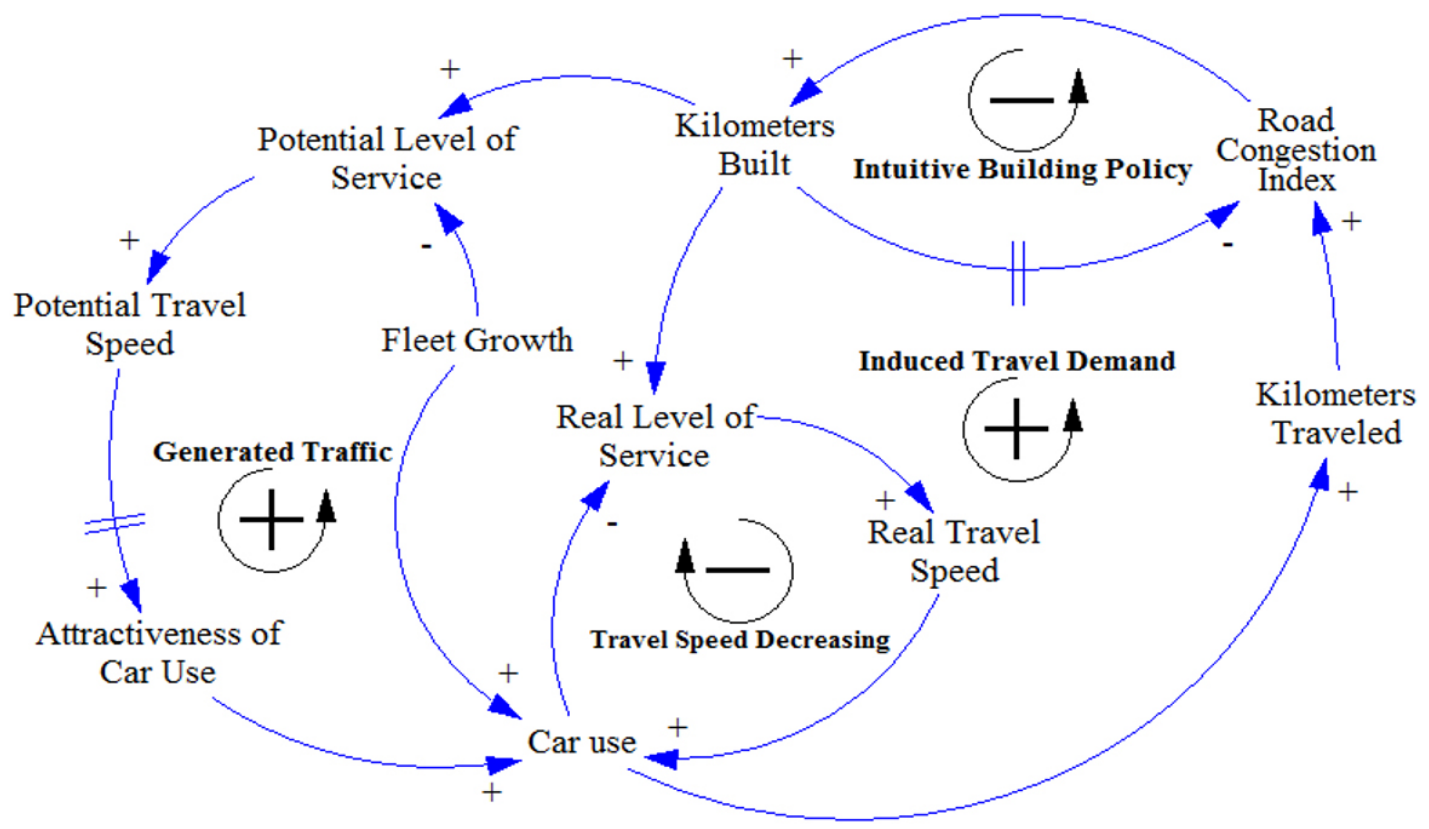

Figure 2: Causal loop diagram: feedback mechanism that structurally explains induced travel demand by road construction

3 Those cars that do not travel because of traffic congestion correspond to discretionary riders who have the option of traveling in more than one means of transport. When mobility is congested, discretionary riders do not use private vehicles; they tend to use other means of transport, such as public transport. 
- Potential Travel Speed: This is the potential speed at which vehicles could travel depending on the Potential Level of Service.

- Attractiveness of Car Use: This variable represents people's satisfaction with respect to Potential Travel Speed that decreases or increases the number of cars in use.

- Car use: This represents the number of vehicles traveling on roads.

- Real Level of Service (LoS): This is used to assess real flow conditions on road infrastructure that change depending on a dimensionless ratio between cars already in use and the vehicles that the kilometers built can hold at an average flow of 3,200 vehicles/hour and a service travel speed of 60 kilometers/hour. The scale of LoS has six discrete values ranging from A to F, which can be seen in Table 1.

- Real Travel Speed: This is the real speed at which vehicles are traveling on roads depending on the Real Level of Service.

- Kilometers Traveled: This is the total kilometers traveled by cars traveling on roads.

According to Figure 2, there are four causal loops. Two of them are reinforcing loops, and the other two are balancing loops. They are described below:

- "Intuitive Building Policy" balancing loop: This loop represents the intuitive decision-making process in which more roads are built to reduce traffic congestion. When the road congestion index (RCI) increases, more kilometers are built to supply more road space, and therefore, traffic congestion is released.

- "Travel Speed Decreasing” balancing loop: This loop depicts how higher travel speeds and benefit of new roads are absorbed by car use. When there are more cars on roads, flow conditions decrease, which results in low travel speed. Lower travel speeds decrease car use until new roads are built again. When this happens, higher travel speeds come back because more road space is available.

- "Generated Traffic" reinforcing loop: In this causal loop, if more roads are built, then the potential level of service increases. Then, potential travel speed increments and attractiveness of car use grows. Consequently, more cars are used, and new traffic is generated, which would happen if new roads were not built. Therefore, there are more cars traveling on new roads, and kilometers traveled increases. As a result, the RCI increases, which induces more road construction.

Table 1. Level of Service and travel speeds. Source: adapted from (Cerquera, 2007)

\begin{tabular}{|c|c|c|c|}
\hline Level of Service & Operating Conditions & Load Factor & Average Travel Speed \\
\hline A & $\begin{array}{l}\text { Individual users are virtually unaffected } \\
\text { by others in the traffic stream. Freedom to } \\
\text { select desired speeds is extremely high. }\end{array}$ & 0.00 to 0.60 & $70 \mathrm{~km} / \mathrm{h}>50 \mathrm{~km} / \mathrm{h}$ \\
\hline $\mathrm{B}$ & $\begin{array}{l}\text { This represents the range of stable flow, } \\
\text { but the presence of other users in the traf- } \\
\text { fic stream begins to be noticeable. }\end{array}$ & 0.61 to 0.70 & $49 \mathrm{~km} / \mathrm{h}>40 \mathrm{~km} / \mathrm{h}$ \\
\hline $\mathrm{C}$ & $\begin{array}{l}\text { This represents the range of stable flow, } \\
\text { but the selection of speed is affected by the } \\
\text { presence of others. }\end{array}$ & 0.71 to 0.80 & $39 \mathrm{~km} / \mathrm{h}>36 \mathrm{~km} / \mathrm{h}$ \\
\hline $\mathrm{D}$ & $\begin{array}{l}\text { This represents high-density but stable } \\
\text { flow. Speed is severely restricted. }\end{array}$ & 0.81 to 0.90 & $35 \mathrm{~km} / \mathrm{h}>30 \mathrm{~km} / \mathrm{h}$ \\
\hline $\mathrm{E}$ & $\begin{array}{c}\text { All speeds are reduced to a low but rel- } \\
\text { atively uniform value. The freedom to } \\
\text { drive within the traffic stream is extremely } \\
\text { difficult. }\end{array}$ & 0.91 to 1.00 & $29 \mathrm{~km} / \mathrm{h}>26 \mathrm{~km} / \mathrm{h}$ \\
\hline $\mathrm{F}$ & This represents forced or breakdown flow. & Greater than 1.00 & $25 \mathrm{~km} / \mathrm{h}$ \\
\hline
\end{tabular}


- "Induced Travel Demand" reinforcing loop: In this loop, when more kilometers are built, more road space is provided. This increases the real level of service and improves real travel speeds. Then, flow conditions for cars that are already in use are improved and vehicles tend to use more new routes and spend more time on them, which means that more kilometers are traveled. Finally, the total numbers of kilometers traveled grow, and RCI increases again. Consequently, more road construction is influenced by higher RCI values.

\subsection{Reference mode}

Based on the causal loop diagram (CLD) proposed, the stocks-flows diagram is formulated to run dynamic simulations of ITD behavior. Qualitative analysis of interactions between CLD's feedback loops allows for a discussion of the expected behavior for simulations of the stocks-slows diagram. This reference pattern, known as reference mode, provides a point of reference during the modeling process, enabling us to stay on track of the model validation and its quantitative results (Ford, 1999).

The reference mode (RM) for the causal loop diagram of section 4.2 can be seen in Figure 3. It is proposed by Litman (2015), and it depicts the generated traffic caused by road construction. According to the RM, traffic grows when roads are uncongested (projected traffic growth line), but the growth rate declines as congestion appears (blue curve), which means that discretionary riders stop using their vehicles. If more roads were built, car use would increase, and traffic would grow again. This additional traffic is called generated traffic (red curve).

\subsection{Simulation model}

The causal loop diagram (CLD) gives a qualitative representation of the model that is useful for describing the ITD structure in terms of the feedback loops formulated. However, decision-making processes require formulating and testing policies in the model to think about their possible effects on ITD. The stocks-flows diagram is the mathematical representation of the CLD using a graphical language of accumulators and pipes, which allows for computer simulation. The stocks-flows diagram can be seen in Figure 4. In addition, types, units and formulas of each variable are shown in Table 2 .

The approach here is based on linking differential equations, which is presented in terms of a graphical language of 'stocks' and 'flows' that keeps the model transparent and easy to understand. Stocks are depicted by rectangles, suggesting a box that holds the content. Flows can be inflow to a stock or outflow from a stock. They are represented with valves that control the rate of flow into or out of the stock. Undergirding the notation of 'stocks' and 'flows' is the mathematical notation that shows how the stock is the integral of inflow minus outflow starting with an initial level of stock. As a stock with inflows and outflows is linked to other stocks and flows, the system structure is described by a set of linked linear and non-linear differential equations.

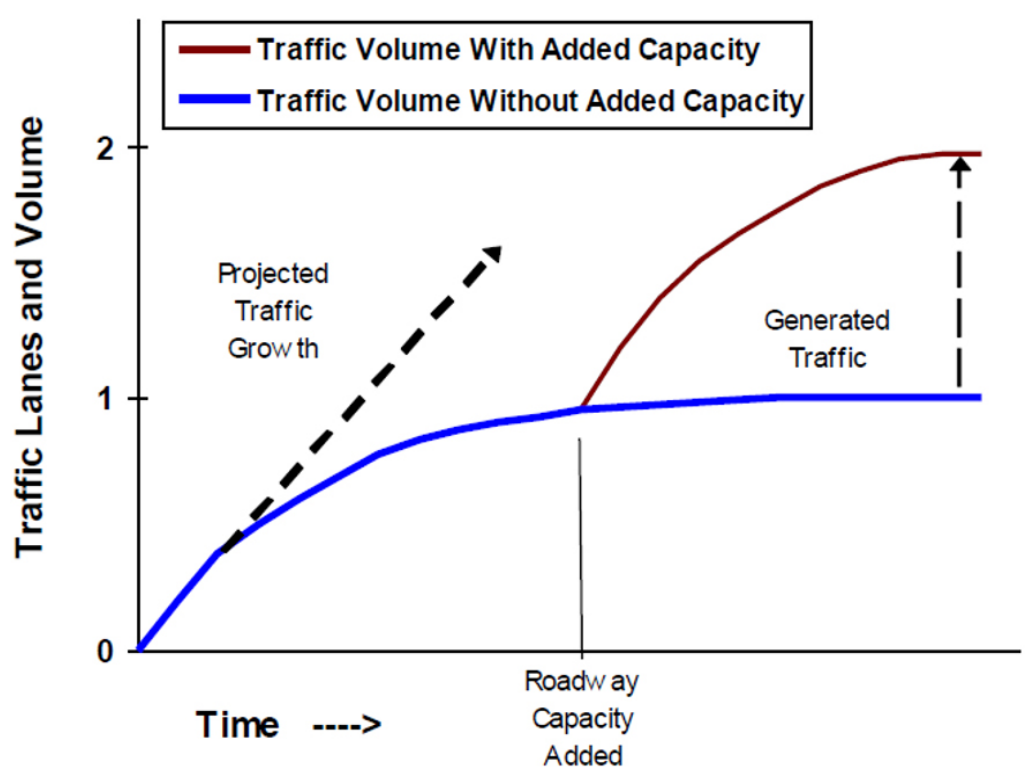

Figure 3: The reference mode for the causal loop diagram proposed in section 4.2. Source: adapted from (Litman, 2015) 


\subsection{Model simulations}

Having formulated both a causal loop diagram and a stocks-flows diagram, this section presents model simulations. These are the quantitative temporal evolution of the model that we have built. The behaviors observed in the graphs below emerge from dynamic relationships between the feedback loops that are described in section 4.2. Before running simulations, we assumed a congested mobility; with this condition, we evaluated two simulation scenarios: a road construction scenario to analyze how new roads induce more motorized travel demand, and a not construction scenario to depict normal travel demand growth without ITD. These hypothetical scenarios are necessary because ITD cannot be evaluated simply by looking

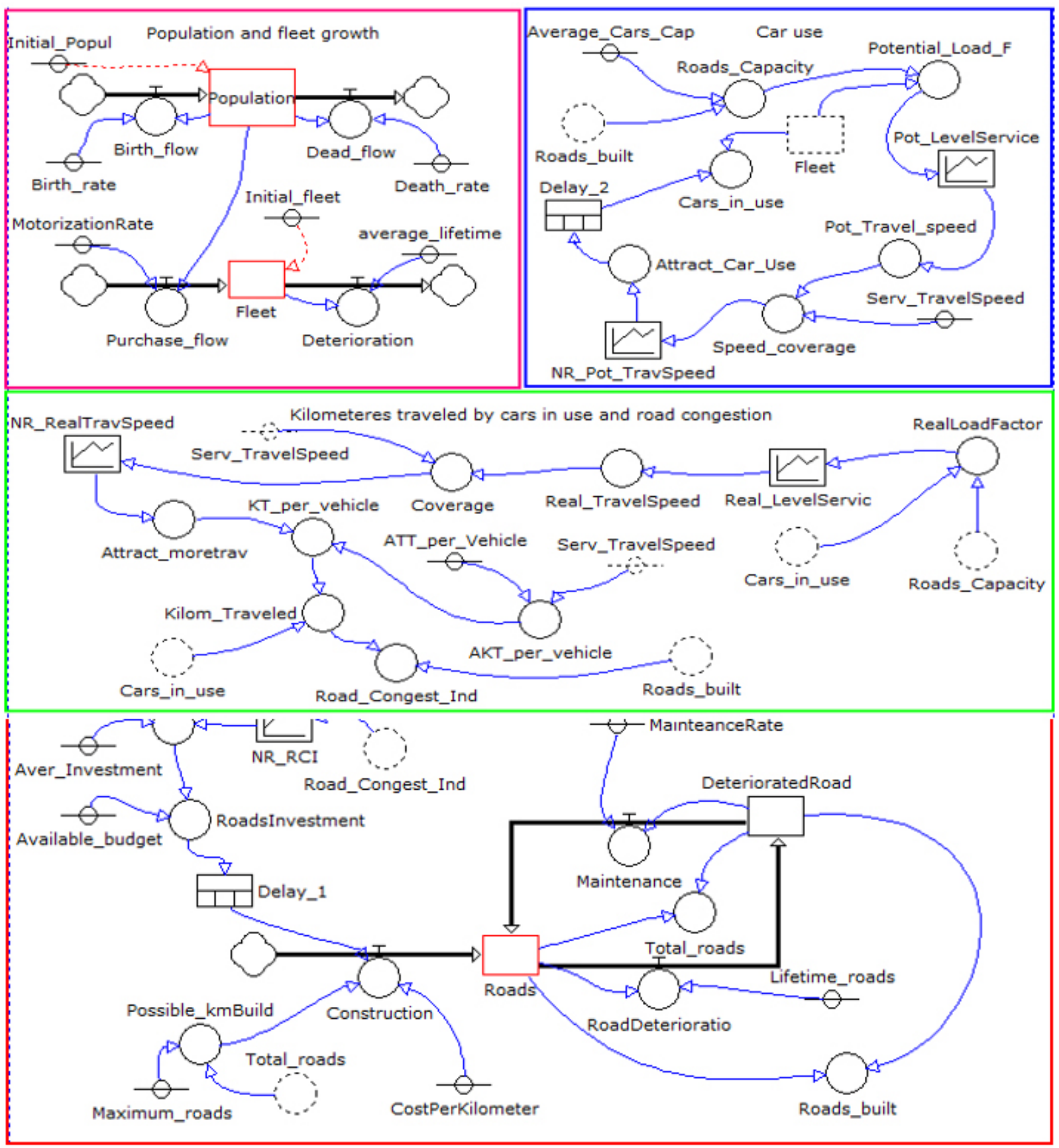

Figure 4: The stocks-flows diagram built on the basis of the feedback structure proposed in section 4.2 
Table 2: Equations of the stocks-flows diagram

\begin{tabular}{|c|c|c|c|}
\hline Type & Variable names & Units & Formulas \\
\hline \multirow{4}{*}{$\begin{array}{l}\frac{\infty}{0} \\
\frac{\partial}{0} \\
=\end{array}$} & Population & People & Initial_Popul \\
\hline & Fleet & Vehicles & Initial_fleet \\
\hline & Roads & Kilometers & 1319 \\
\hline & DeterioraedRoads & Kilometers & 100 \\
\hline \multirow{7}{*}{$\frac{\sum_{0}^{\infty}}{1}$} & Birth_flow & People/year & Birth_rate*Population \\
\hline & Construction & Kilometers/year & MIN(Possible_kmBuild,(Delay_1/CostPerKilometer)) \\
\hline & Dead_flow & People/year & Population*(Death_rate) \\
\hline & Deterioration & Vehicles/year & Fleet/average_lifetime \\
\hline & Maintenance & Kilometers/year & DeterioratedRoad/MaintenanceRate \\
\hline & RoadDeterioratio & Kilometers/year & Roads/Lifetime_roads \\
\hline & Purchase_flow & Vehicles/year & Population*MotorizationRate \\
\hline \multirow{15}{*}{ 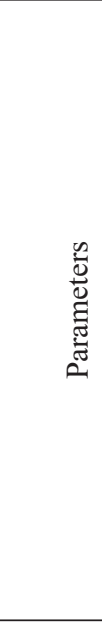 } & ATT_per_Vehicle & Hour & 0.53 \\
\hline & Available_budget & US dollars & 510638297 \\
\hline & Aver_Investment & Percentage fraction & 1 \\
\hline & Average_Cars_Cap & Vehicles/Kilometer & 53 \\
\hline & Birth_rate & Dimensionless/year & 0.1911 \\
\hline & CostPerKilometer & US dollars & 1200 \\
\hline & Death_rate & Dimensionless/year & 0.0556 \\
\hline & Initial_Popul & People & 1113522 \\
\hline & Initial_fleet & Vehicles & 492299 \\
\hline & Lifetime_roads & Years & 15 \\
\hline & MainteanceRate & Years & 1.1 \\
\hline & Maximum_roads & Kilometers & 500000 \\
\hline & MotorizationRate & Vehicles/people & 0.023 \\
\hline & Serv_TravelSpeed & Kilometers/hour & 60 \\
\hline & average_lifetime & Years & 12 \\
\hline \multirow{19}{*}{ 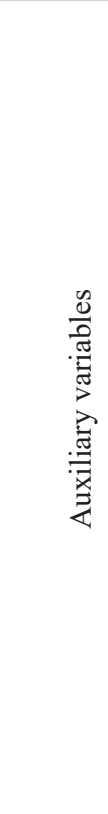 } & AKT_per_vehicle & Kilometers & (ATT_per_Vehicle*Serv_TravelSpeed) \\
\hline & Attract_Car_Use & Dimensionless & NR_Pot_TravSpeed \\
\hline & Attract_moretrav & Dimensionless & NR_RealTravSpeed \\
\hline & Budget_allocated & Percentage fraction & NR_RCI*Aver_Investment \\
\hline & Cars_in_use & Vehicles & Fleet*Delay_2 \\
\hline & Coverage & Dimensionless & Real_TravelSpeed/Serv_TravelSpeed \\
\hline & KT_per_vehicle & Kilometers/vehicle & (AKT_per_vehicle*Attract_moretrav) \\
\hline & Kilom_Traveled & Kilometers & (Cars_in_use* KT_per_vehicle) \\
\hline & Possible_kmBuild & Kilometers & $\begin{array}{l}\text { IF(Maximum_roads-Total_roads }<=0,0, \text { Maximum } \\
\text { roads-Total_roads) }\end{array}$ \\
\hline & Pot_Travel_speed & Kilometers/hour & Pot_LevelService \\
\hline & Potential_Load_F & Dimensionless & Fleet/Roads_Capacity \\
\hline & RealLoadFactor & Dimensionless & Cars_in_use/Roads_Capacity \\
\hline & Real_TravelSpeed & Kilometers/hour & Real_LevelServic \\
\hline & Road_Congest_Ind & Dimensionless & (Kilom_Traveled/Roads_built)/8045 \\
\hline & RoadsInvestment & US dollars & Available_budget*Budget_allocated \\
\hline & Roads_Capacity & Vehicles & (Roads_built*Average_Cars_Cap) \\
\hline & Roads_built & Kilometers & $($ Roads $+(0.5 *$ DeterioratedRoad $))$ \\
\hline & Speed_coverage & Dimensionless & Pot_Travel_speed/Serv_TravelSpeed \\
\hline & Total_roads & Kilometers & DeterioratedRoad+Roads \\
\hline
\end{tabular}


Table 2: Equations of the stocks-flows diagram (continued)

\begin{tabular}{|c|c|c|c|}
\hline \multirow{5}{*}{ 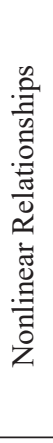 } & NR_Pot_TravSpeed & Dimensionless & $\begin{array}{l}\text { INTSPLINE }(2,0,0.05,0.5,0.5,0.5,0.5,0.5,0.5,0.5,0.5,0 . \\
5,0.5,0.5,0.7,0.7,0.8,0.85,0.9,0.9,0.9,0.95,1,1,1,1,1,1,1 \\
1,1,1,1,1)\end{array}$ \\
\hline & NR_RCI & Dimensionless & $\begin{array}{l}\text { INTSPLINE }(2,0,0.01,1,1,1,1,1,1,1,1.1,1.15,1.2,1.3,1.3 \\
30416,1.483599,1.5,1.5,1.5)\end{array}$ \\
\hline & NR_RealTravSpeed & Dimensionless & $\begin{array}{l}\text { INTSPLINE }(2,0,0.05,0.5,0.5,0.5,0.5,0.5,0.5,0.5,0.5,0.5 \\
, 0.5,0.5,0.7,0.7,0.8,0.85,0.9,0.9,0.9,0.95,1,1.2,1.2,1.25,1 \\
.25,1.3,1.3,1.3,1.3,1.3,1.3,1.3) \\
\end{array}$ \\
\hline & Pot_LevelService & Dimensionless & $\begin{array}{l}\text { INTSPLINE }(2,0,0.01,70,70,67,60,57,55,50,48,36,30,2 \\
5,25,25,25,25)\end{array}$ \\
\hline & Real_LevelServic & Dimensionless & $\begin{array}{l}\text { INTSPLINE }(2,0,0.01,70,70,67,60,57,55,50,48,36,30,2 \\
5,25,25,25,25)\end{array}$ \\
\hline \multirow{2}{*}{ 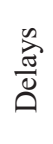 } & Delay_1 & Years & RETARDO (RoadsInvestment, 10,5,1) \\
\hline & Delay_2 & Years & RETARDO (Attract_Car_Use, $1,1,0$ ) \\
\hline
\end{tabular}

at how actual road conditions evolve; instead, motorized travel is considered to be induced if it is shown that there is more travel demand occurring when new roads are built (Gorham, 2009). In addition, the simulation scenarios do not seek to match a set of accurate outputs; instead, they allow validating in the way that the feedback structure reproduces ITD behaviors that are reported in econometric literature.

The road congestion index (RCI) can be seen in Figure 5. Its behavior shows the state of mobility through a time horizon of 15 years in axis $\mathrm{X}$. Axis $\mathrm{Y}$ is the ratio between kilometers traveled by cars and kilometers built. The road construction scenario at the beginning of the time horizon has high RCI values because of the time delay required to finish the construction of new roads (blue curve). Then, the RCI starts to decrease until values near 0.1 . The expected results of building roads become evident between 2018 and 2022. However, the unintended consequences of new roads appear after that time interval. Higher travel speeds increase attractiveness of car use, and mobility tends to be congested again. For the not construction scenario, RCI values always tend to increase because there is not enough space to supply the demanded capacity by the normal fleet growth (red curve), which can be influenced either by economic or social elements that are not considered in the proposed model.

These results in both scenarios come from the feedback loop named "Intuitive Building Policy", which is shown in Figure 6. This loop reflects the traditional decision-making process wherein building roads can keep ahead of traffic congestion. However, such policy only releases mobility temporarily (Figure 5). In a long-term time horizon, congestion appears again with equal or worse values than its previous state.
The reference mode on the left side of Figure 7 shows how building new roads generates new traffic. This behavior can be explained through the feedback loop in Figure 8 wherein road construction improves potential travel speed and increases the attractiveness of car use. This feedback loop produces the blue curve behavior that was observed for the road construction scenario in the graph on right side of Figure 7. For the not construction scenario (red curve) in Figure 7, the attractiveness of car use is not influenced by potential travel speed improvements; therefore, the car use curve for this scenario has lower values than the blue curve.

The new traffic that is generated by road construction implies that there will be more cars on roads, and therefore, more kilometers will be traveled, which can be seen in Figure 9 (red curve). However, it is important to notice that the total kilometers traveled start to increase before the year 2020 before potential travel speed generates new traffic after 2020 (blue curve on the right side of Figure 7). This happens because new roads improve real travel speed at which cars already in use are traveling. Consequently, higher travel speeds induce people to travel more kilometers, which can be structurally explained in the "Induced Travel Demand" loop of Figure 10. For the case of the not road construction scenario in Figure 9 (blue curve), the increase of kilometers traveled is lower than the red curve. There are two reasons that can justify this behavior. First, without new roads, mobility remains congested, and there is no high real travel speed that can induce cars that are already in use to travel more kilometers. Second, without road construction, there is no potential travel speed that generates new traffic. 


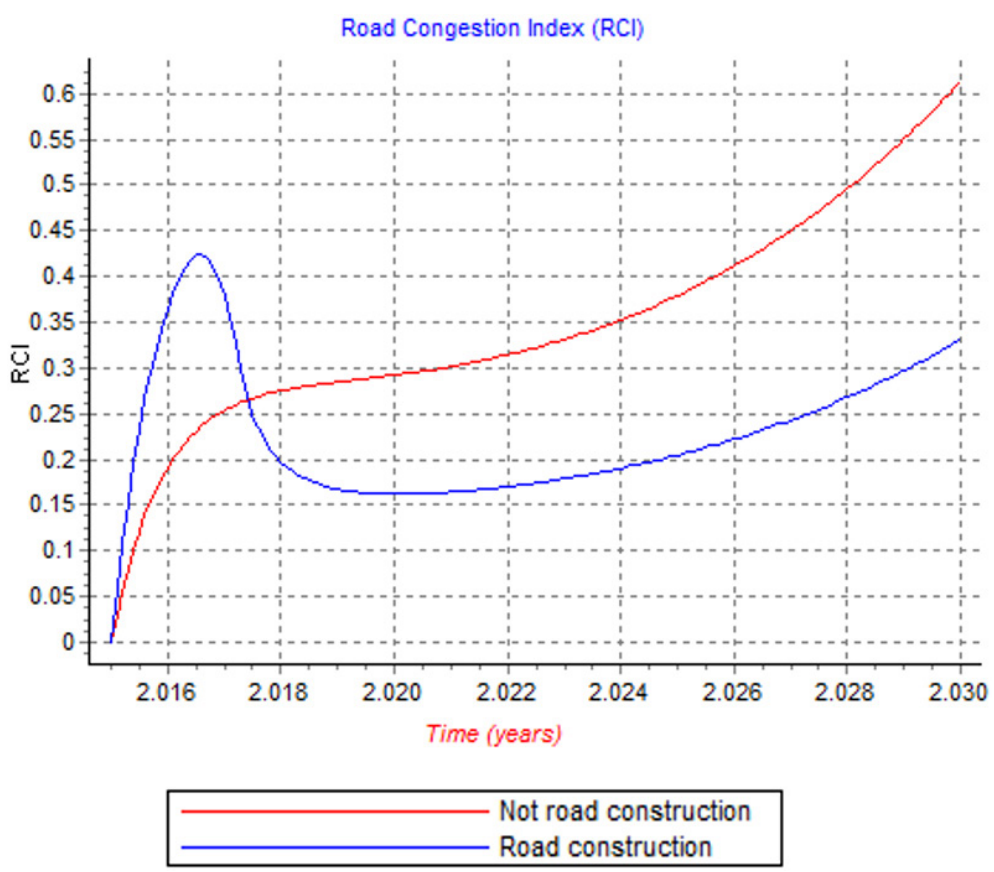

Figure 5. Road congestion index generated by "Intuitive Building Policy" balancing loop

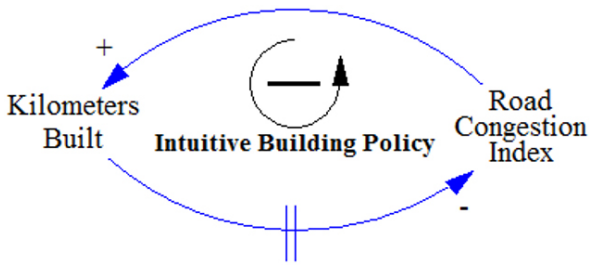

Figure 6. "Intuitive Building policy" balancing loop

Finally, Figure 11 shows the real travel speed behavior for the road construction scenario and the not construction scenario. In the first scenario, travel speed has lower values at the beginning of the time horizon when the RCI is higher (Figure 5). When the time delay of building new roads has finished, the real travel speed enhances car use. Nevertheless, at the end of the time horizon, the travel speed decreases because car use saturates roads' capacity again. In the case of the not road construction scenario (red curve), travel speed values are lower than the blue curve because without new roads the normal fleet growth congests mobility rapidly. This behavior can be explained by means of the causal loop shown in Figure 12, which depicts how travel speed is absorbed by car use. Such car use is composed of induced travel demand and generated traffic.

\section{Discussion}

Questions about causal links between traffic and road construction require a look beyond the statistical relationship of kilometers traveled and kilometers built. The ITD phenomenon has already been measured and corroborated but not structurally explained at all. Causality is not the main purpose of econometric models (Concas, 2013). However, some authors have dealt with causality through the Granger test and instrumental variables in least squares of two and three stages (Cervero and Hansen, 2002; Cervero and Hansen, 2000; Hymel et al., 2010; Melo et al., 2012; Noland and Cowart, 2000; Özuysal et al., 2008). Although these techniques deal with causality, it is necessary to gain more insight into the structural complexity of ITD to improve policy design to address this phenomenon. System dynamics offers to explain such complexity with feedback loops, non-linear relationships and delays that represent lag responses of people with respect to flow improvements of new roads. These modeling tools fit better with ITD if it 


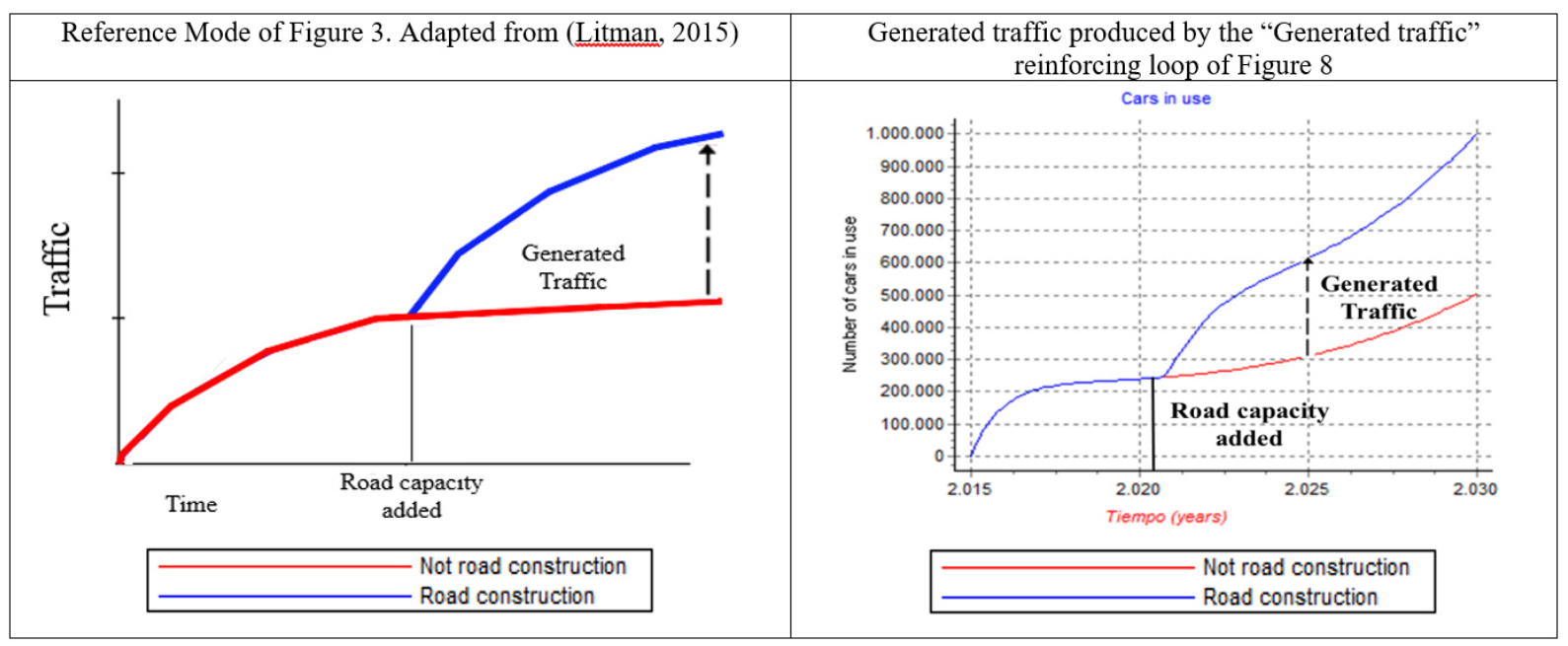

Figure 7: Reference mode and "Generated traffic" loop behavior

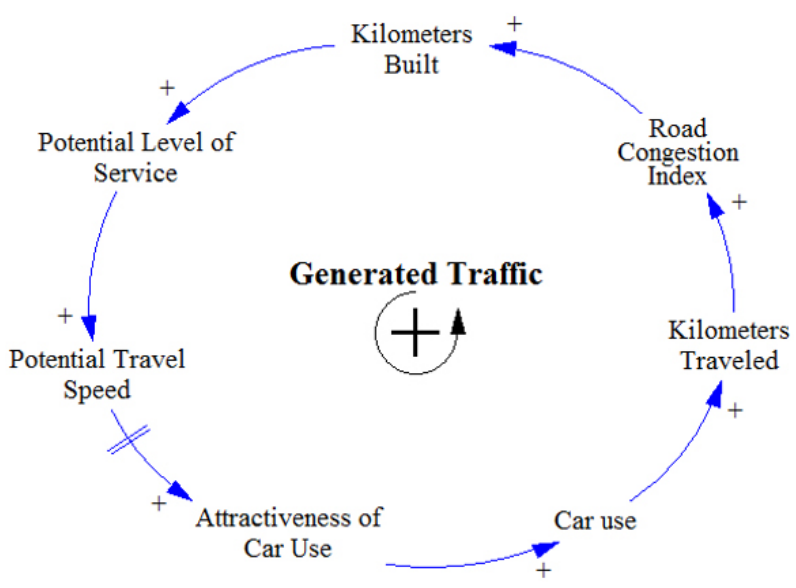

Figure 8: "Generated traffic" reinforcing loop

is assumed to be a social phenomenon that involves people's behavior and the way in which they travel.

Based on the evidence provided by econometric works, it is possible to propose a systemic representation of ITD. Simulation results that come from the feedback structure of the system dynamics model that was built show two ITD behaviors. In the short term, cars already in use travel more kilometers. This short-term ITD refers to conscious decisions made by drivers to take advantage of flow condition improvements created by new roads, which the "induced travel demand" loop shows in Figure 10. Some authors classify this type of ITD as direct induced travel demand (Gorham, 2009). Several studies have used elasticities to quantify the increments of kilometers traveled, which are induced by road construction. Elasticity measures usually range from 0.3 to 0.6 , depending on the urban context studied (Concas, 2013; Handy, 2014; He and Zhao, 2014; Litman, 2015; Shengchuan; 2012).
In addition, the simulation results depict a medium-term ITD that matches with the reference mode in section 4.3. Duranton and Turner (2011), in their work named "the law of road congestion", argue that building roads can create new travelers. These new travelers are the generated traffic produced by the "Generated Traffic" loop when travel speed, one engine of car use growth (Bleijenberg, 2012), increases attractiveness of car use. Consequently, more cars are going to travel on new roads, which, when added to vehicles already in use, saturate mobility again in a long-term time horizon, which is shown in the road congestion index of Figure 5. Gorhman (2009) classifies this type of ITD as indirect induced travel demand, which has statistically been measured through elasticities that mostly fall into the range from 0.6 to 1.0 (Cervero and Hansen, 2002; Duranton and Turner, 2011; He and Zhao, 2014; Noland, 2001; Noland and Cowart, 2000).

It is clear that econometric models based on elasticities 


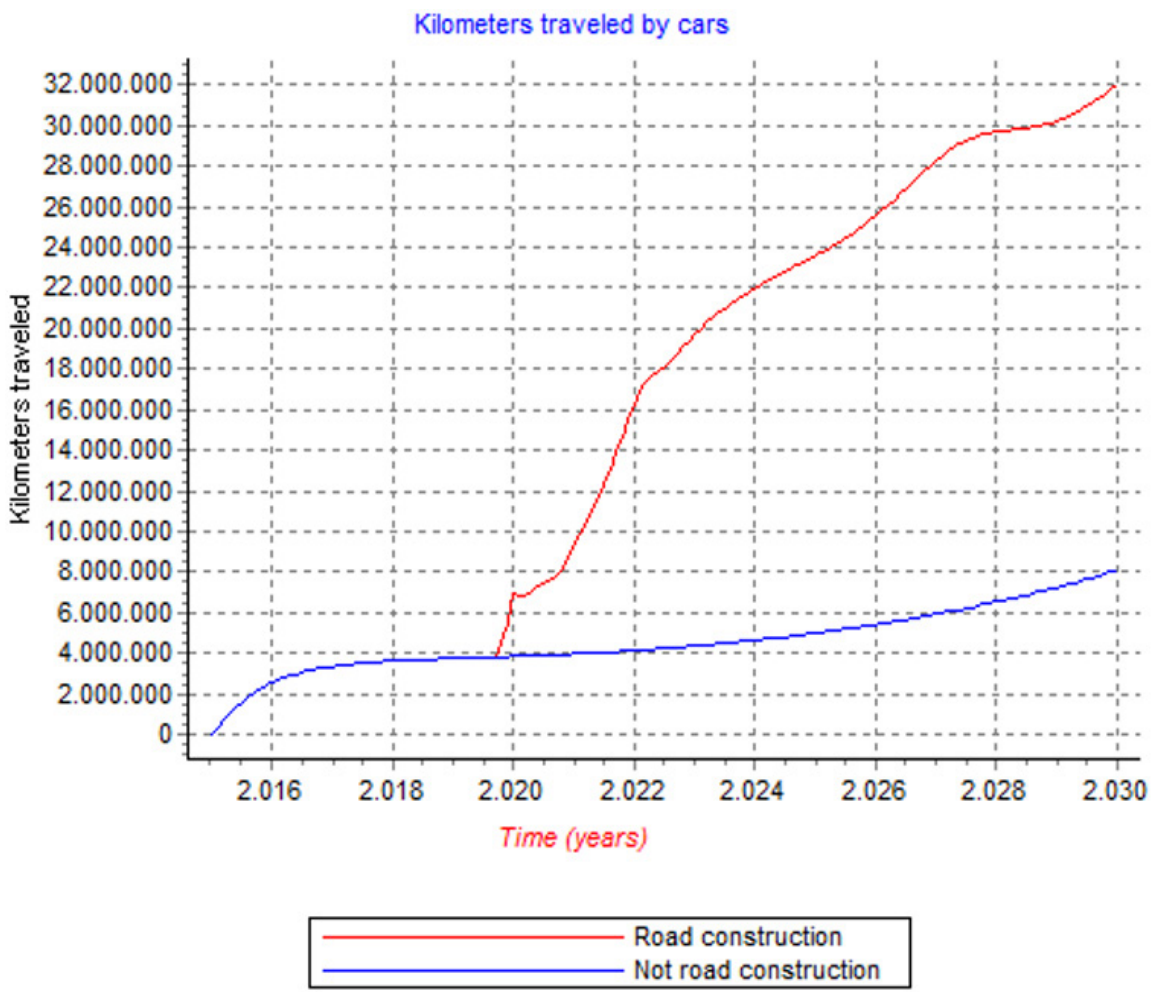

Figure 9: Kilometers traveled generated by the "Induced Travel Demand" reinforcing loop

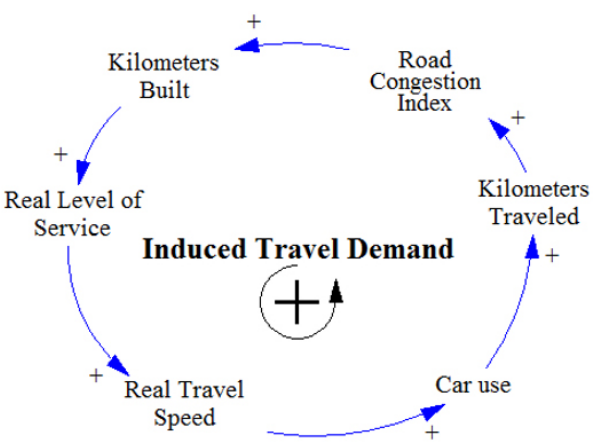

Figure 10: "Induced Travel Demand" reinforcing loop

show how responsive travel demand is to road construction. Such estimations corroborate the existence of ITD at a microeconomic level and the way in which it increases trip-making. Nevertheless, ITD does not refer to people making more frequent trips; instead, the term refers to the overall amount of motorized travel undertaken because of new roads creation (Gorham, 2009). In this sense, the system dynamics model that we proposed complements previous literature results because the ITD behaviors described above emerge at an aggregate level, motorized travel as a whole instead of focusing on quantifying discrete trip increases after road construction as econometric models have done until now. Model simulations do not seek to accomplish a level of accuracy in their results; instead, their feedback structure clarifies the structural complexity underlying the results that are obtained with elasticities in other works. In this context, the model built can be conceived as a structural explanation of ITD based on one premise of the systems dynamics paradigm: similar structures correspond to similar behaviors (Andrade et al., 2001; Forrester, 1971). 

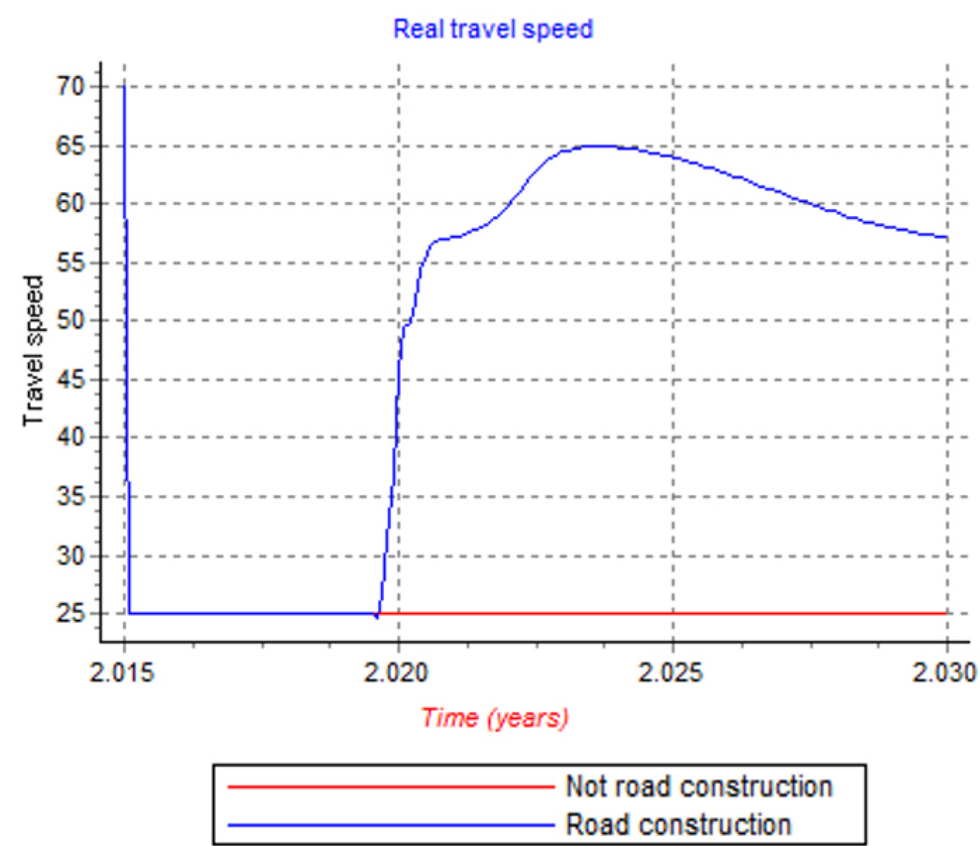

Figure 11: Real travel speed behavior generated by the "Travel Speed Decreasing" balancing loop

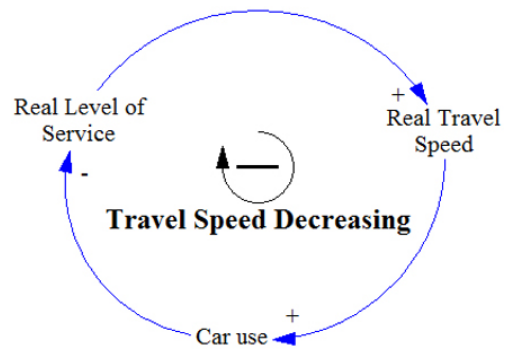

Figure 12: "Travel Speed Decreasing” balancing loop

\section{Conclusions}

Approaching induced travel demand (ITD) with a systemic perspective allows us to identify leverage points that contribute to comprehensive design policies aimed to cope with this phenomenon. The main contribution of this work lies in obtaining a fundamental understanding of the structural complexity underlying ITD. Understanding such complexity is valuable when unintended consequences of road construction are unknown, and though road construction in developed countries is no longer an exclusive policy to reduce congestion, in many developing countries, rapid urban sprawl, high population growth, raised motorization rates and traffic congestion have promoted a perceived need for more roads, which would enhance car use among transport policy-makers.

Although the more general concept of induced travel applies to the entire transportation sector, not just to one mode, motorized travel demand supplied with new roads needs special attention because of the economic, social and environmental consequences of both road construction and intensive car use. Policy-makers in developing countries could argue that road construction is a policy that at least can keep ahead of growing traffic congestion. Nevertheless, based on simulation results it is possible to state that a transport conception that depends mainly on private vehicles as the predominant means of transport is condemned to be trapped inside traffic congestion. Regardless of how much road capacity strategic planning provides, higher travel speeds coming from new roads are absorbed by ITD in a short- and medium-term time horizon.

To escape from such transport conception requires creating a new and sustainable transport conception that goes beyond the old transport planning paradigm in which road construction seeks to improve mobility, maximizing motor vehicle travel speeds and affordability. Although the feedback structure that is proposed in this paper is a structural explanation of ITD, the structure's center is based on 
cars and travel speed as measures of travel performance. Therefore, future work must focus on moving the structure's center from private vehicles to people. This allows for a conversation about accessibility for people rather than mobility attached to cars traveling at high speeds. In addition, the model boundaries should be expanded to consider alternative strategies beyond road construction to address traffic congestion and ITD within developing urban contexts wherein road construction is still necessary to guarantee connectivity.

\section{Literature}

Andrade, H. H., Dyner, I., Espinosa, A., López, H., \& Sotaquirá, R. (2001). Pensamiento Sistémico: Diversidad en búsqueda de Unidad. Bucaramanga, Colombia: Ediciones Universidad Industrial de Santander.

Andrade, H. H., Navas, X., Maestre, G., \& López, G. (2014). El modelado y la simulación en la escuela $-D e$ preescolar a undécimo grado construyendo explicaciones cientificas. Bucaramanga, Colombia: Ediciones Universidad Industrial de Santander.

Barlas, Y. (1996). Formal aspects of model validity and validation in system dynamics". System Dynamics Review, 12(3), 183-210, http://dx.doi.org/10.1002/(SICI)10991727(199623)12:3<183::AID-DR103>3.0.CO;2-4

Bleijenberg, A. (2012). Chapter 2: The Attractiveness of Car Use. Cars and Carbon (pp. 19) 2012, http://dx.doi. org/10.1007/978-94-007-2123-4_2

Bunge, M. (2014). Big questions come in bundles, hence they should be tackled systemically. Systema: connecting matter, life, culture and technology, 2(2). Retrieved October 1, 2015, from www.systema-journal.org/article/view/346

Cerquera, F. (2007). Capacidad y niveles de servicio de la infraestructura vial. Universidad Pedagógica y Tecnológica de Colombia, Escuela Ingeniería de Transporte y Vías, Colombia. Retrieved June 22, 2015, from http://virtual.uptc.edu.co/drupal/files/48.pdf

Cervero, R. (2001). Road Expansion, Urban Growth, and Induced Travel: A Path Analysis. Journal of the American Planning Association, 69(2), 145-163, http://dx. doi.org/10.1080/01944360308976303

Cervero, R., \& Hansen, M. (2000). Road supply-Demand relationships: Sorting out causal linkages. Institute of Transportation Studies, University of California, Berkeley. Retrieved October 22, 2015, from www. uctc.net/research/papers/444.pdf

Cervero, R., \& Hansen, M. (2002). Induced travel demand and induced road investment - a simultaneous equation Analysis. Journal of Transport Economics and Policy, 36(3), 469-490. ISSN: 00225258.

Concas, S. (2013). Highway capital expenditures and induced vehicle travel. Transportation Research Board 92nd Annual Meeting, Washington D.C., January 13-
17. Retrieved October 22, 2015, from http://papers. ssrn.com/sol3/papers.cfm?abstract id=2062599

Currie. G., \& Delbosc A. (2010). Literature review of induced travel. Institute of transport and logistics studies. Working paper, ISSN: 1832-570X. Retrieved September 25,2015 , from www.sydney.edu.au/business/ data/assets/pdf file/0004/75181/itls-wp-10-16.pdf

Duranton, G., \& Turner, M. A. (2011). The fundamental law of road congestion: Evidence from US Cities. American Economic Review, 101(6), 2616-2652, http://dx.doi.org/10.1257/aer.101.6.2616

Ford, A. (1999). Modelling the environment. An Introduction to system dynamics. Models of environmental systems. Washington DC, USA: Island Press. ISBN: 1-55963-601-7.

Forrester, J. 1994. Learning through System Dynamics as preparation for the 21st century. Keynote Address for Systems Thinking and Dynamic Modeling Conference for K-12 Education, Concord, MA, USA. Retrieved October 8, 2015, from http://ocw.mit.edu/courses/ sloan-school-of-management/15-988-system-dynamics-self-study-fall-1998-spring-1999/readings/learning2.pdf

Forrester, J. W. (1969). Urban Dynamics. Portland, USA: Productivity Press.

Forrester, J. W. (1971). Counterintuitive behavior of social systems. Theory and Decision, 2(2), 109-140, http:// dx.doi.org/10.1007/BF00148991

Goodwin, P. P. (1992). A review of new demand elasticities with special reference to short and long run. Journal of Transport Economics and Policy, 26(2), 155-169. Retrieved October 1, 2015, from www.bath.ac.uk/e-journals/jtep/pdf/Volume_XXV1_No_2 155-169.pdf

Gorham, R. (2009). Demystifying induced travel demand. Sustainable Transportation Technical Document, Sustainable Urban Transportation Project. Germany. Retrieved October 22, 2015, from http://www.sutp. org/files/contents/documents/resources/B Technical-Documents/GIZ SUTP TD1_Demystifying-Induced-Travel-Demand EN.pdf

Graham, D. J., McCoy, E. J., \& Stephens, D. A. (2014). Quantifying causal effects of road network capacity expansions on traffic volume and density via a mixed model propensity score estimator. Journal of the American Statistical Association, 109(508), 1440-1449, http://dx.doi.org/10.1080/01621459.2014.956871

Handy, S. (2014). Impact of Highway Capacity and Induced Travel on Passenger Vehicle Use and Greenhouse Gas Emissions. California Environmental Protection Agency, Air Resources Board, Retrieved August 28, 2015, from www.arb.ca.gov/cc/sb375/policies/hwycapacity/highway capacity brief.pdf

Hansen, M. (1995). Do new highways generate traffic? ACCESS Magazine 7, 16 - 23. Retrieved August 15, 2015, from www.accessmagazine.org/articles/fall1995/do-new-highways-generate-traffic/ 
He, N., \& Zhao, S. (2014). Induced Traffic in China: Elasticity Models with Panel Data. Journal of Urban Planning and Development, 141(4), http://dx.doi. org/10.1061/(ASCE)UP.1943-5444.0000265

Hills, P. (1996). What is induced traffic? Transportation, 23(1), 5-16. http://dx.doi.org/10.1007/BF00166216

Hong, Y., Liyin, S., Yongtao, T., \& Jianli, H. (2011). Simulating the impacts of policy scenarios on the sustainability performance of infrastructure projects. Automation in Construction, 20(8), 1060-1069, http://dx.doi. org/10.1016/j.autcon.2011.04.007

Hymel, K. M., Small, K. A., \& Van Dender, K. (2010). Induced demand and rebound effects in road transport. Transportation Research Part B, 44(3), 1220-1241, http://dx.doi.org/10.1016/j.trb.2010.02.007

Ladd, B. (2012). You can't build your way out of congestion. - Or can you? disP - The Planning Review, 48(3), 16-23, http://dx.doi.org/10.1080/02513625.201 2.759342

Litman, T. (2012). Changing Vehicle Travel Price Sensitivities - The Rebounding Rebound Effect. Victoria Transport Policy Institute. Retrieved October 8, 2015, from www.vtpi.org/VMT_Elasticities.pdf

Litman, T. (2015). Generated Traffic and Induced Travel - Implications for Transport Planning. Victoria Transport Policy Institute. Retrieved August 25, 2015, from www.vtpi.org/gentraf.pdf

Melo, P. C., Graham, D. J., \& Canavan, S. (2012). The Effects of Road Investments on Economic Output and Induced Travel Demand: Evidence for Urbanized Areas in the US. Transportation Research Record: Journal of the Transportation Research Board 2292(20), 163171, http://dx.doi.org/10.3141/2297-20

Noland, R. B. (2001). Relationships between highway capacity and induced vehicle travel. Transportation Research Part A, 35(1), 47-72, http://dx.doi.org/10.1016/ S0965-8564(99)00047-6

Noland, R. B. (2004). Transport Policy and Assessment Procedures in the United Kingdom: Lessons for the Federal District of Mexico City. Retrieved September 25, 2015, from www.itdp.org/wp-content/uploads/2014/07/12.-Mex-White-Paper UK.pdf

Noland, R. B., \& Cowart, W. A. (2000). Analysis of Metropolitan Highway Capacity and the Growth in Vehicle Miles of Travel. Transportation, 27(4), 363-390, http:// dx.doi.org/10.1023/A:1005288826997

Noland, R. B., \& Lem, L. L. (2002). A review of the evidence for induced travel and changes in transportation and environmental policy in the US and the UK. Transportation Research Part D: Transport and Environment, 7(1), 1-26, http://dx.doi.org/10.1016/S1361$\underline{9209(01) 00009-8}$

Observatorio Metropolitano de Bucaramanga. (2014). Sustentabilidad Ambiental Urbana, Movilidad Sustentable. Bucaramanga, Colombia. Retrieved August 25, 2015, from www.amb.gov.co/observatorio2/indi-
cadores/sau/Infograf\%C3\%ADa\%208\%20-\%20Movilidad $\% 20$ sustentable.pdf

Özuysal, M., \& Tanyel, S. (2008). Induced Travel Demand in Developing Countries: Study on State Highways in Turkey. Journal of urban planning and development, 134(2), 78-87, http://dx.doi.org/10.1061/(ASCE)07339488(2008)134:2(78)

Secretaría de Infraestructura de Bucaramanga. (2011). Mesa de sostenbilidad urbana. Bucaramanga, Colombia. Retrieved June 22, 2015, from www.findeter.gov. co/descargar.php?idFile $=210392$

Shengchuan, Z., Nan, H., \& Ning, L. (2012). An Analysis of Induced Traffic Effects in China. The Planning Review, 48(3), 54-63, http://dx.doi.org/10.1080/0251362 5.2012 .759350

Sterman, J. (2000). Business Dynamics: Systems Thinking and Modeling for a Complex World. USA: Irwin McGraw-Hill.

Juan S. Angarita-Zapata, systems engineer graduated from Universidad Industrial de Santander (UIS), Colombia. Currently, he is doing his master degree in systems engineering at UIS. Member of both the Colombian and the Latin American communities of System Dynamics (SD). Active member of System Dynamics Society. Researcher in the area of mathematical modeling and simulation with SD. Author of national and international academic event publications related to urban transport, environment, education and production systems approached from systems thinking and SD.

Hugo H. Andrade-Sosa, full professor and researcher at Universidad Industrial de Santander (UIS), Colombia, in the areas of systems thinking, and mathematical modeling and simulation with System Dynamics (SD). Author of publications in national and international academic events, as well as academic journals. He is the director and founder of SIMON Research Group at UIS, member of the System Dynamics Society, and member of the Colombian and Latin American community of System Dynamics.

Jorge A. Parra-Valencia, professor and researcher at Universidad Autónoma de Bucaramanga (UNAB), Colombia. Member of the Research Group on Systems Thinking at UNAB. Currently, he is President of the Colombian Community of System Dynamics. His research areas are focused on systems thinking, system dynamics and systems engineering. In recent years, his professional and research work has focused on the formulation and implementation of research projects, development of simulation experiments, and designing models to understand and improve social systems. 